\title{
Malposition Reconstruction of Saphena Vein Grafts Used for Coronary Artery Bypass and Pericardial Fat Tissue
}

\author{
Mehmet Aksut ${ }^{1}$, Davut Cekmecelioglu*11, Kamil Boyacioglu ${ }^{2}$, Kaan Kirali ${ }^{1}$ \\ ${ }^{1}$ Department of Cardiovascular Surgery, Kartal Kosuyolu Yuksek Ihtisas Research and Training Hospital, Turkey \\ ${ }^{2}$ Department of Cardiovascular Surgery, Bagcilar Research and Training Hospital, Turkey
}

Received: May 28, 2018; Published: June 06, 2018

*Corresponding author: Davut Cekmecelioglu, Department of Cardiovascular Surgery, Kartal Kosuyolu Yuksek Ihtisas Egitim ve Arastirma Hastanesi, Turkey

\begin{abstract}
The saphena vein grafts used in coronary artery bypass grafting operations are used in majority of patients because of the need for multiple grafts and the high level of availability. The graft deficiency observed in saphena vein grafts especially because of the surgical technic reasons is one of the most important limiting factors of these operations. We aimed to represent our reconstruction method in order to prevent the malposition because of incompliance between the graft size and the required size, and the consequent possible early deficiencies. The stem cell content and secondary contributions of pericardial fat tissue, which is our reconstruction material that can be applied easily, fast, and effectively, are among the promising achievements of our practice.
\end{abstract}

Keywords: Pericardial Fat Tissue; Graft Patency; CABG; Graft Reconstruction

Abbevations: CABG: The Coronary Artery Bypass Grafting; SVG: Saphena Vein Grafts; CASS: Coronary Artery Surgery Study; CPB: Cardiopulmonary Bypass

\section{Introduction}

The coronary artery bypass grafting (CABG) is one of the most frequently implemented surgical operations $(400,000$ operations per year) in the USA.1 In the coronary artery bypass grafting operations, the first successful applications of saphena vein grafts (SVG) were performed in 1964 [1,2]. The saphena vein grafts are the highly available and multi-purpose grafts. On the contrary with arterial grafts, they are resistant to the intraoperative and perioperative spasms. Because of the need for multi-purpose graft and high availability, the SVG is still widely used for many patients undergone CABG operations [1]. Although CABG improves the survival and symptoms among the selected patients [2-4] the deficiency of saphena vein graft (SVG) limits the long-term success of surgical coronary revascularizations [1]. The study of Coronary Artery Surgery Study (CASS) revealed that the graft opening reached at $90 \%$ on 60 th day and $82 \%$ within 18 months [3]. In 10 years, more than $50 \%$ of grafts are occluded. In this report, we aimed to represent our easy, fast, and effective method regarding the graft malposition, which is one of the factors causing saphena vein deficiency (Figure 1).

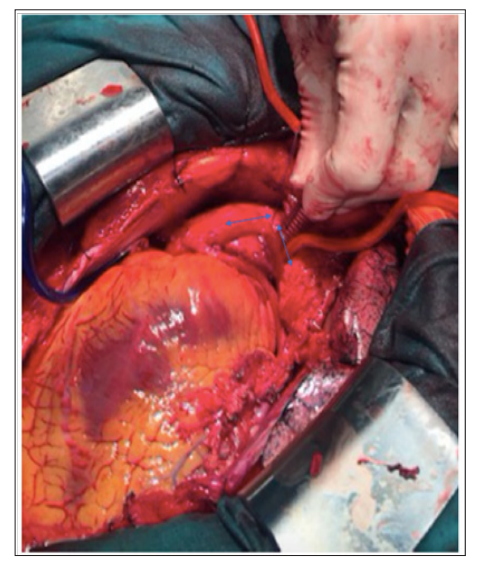

Figure 1 : Kinking of saphena vein graft after compilation of anastomosis.

\section{Graft Deficiency in CABG and the Technical Reasons}

The bypass graft deficiencies after the coronary artery bypass surgery are classified as early-period deficiencies and late-period 
deficiencies. The early (less than 1 month) and sub-acute (up to 12 months) graft deficiency are observed because of thrombosis, surgical technique failures, and intimal hyperplasia. The surgical technique failures in intraoperative processes such as removal of saphena vein graft, graft manipulation, and graft implantation might cause endothelial dysfunction, inflammation, and consequently the graft occlusion [5]. The most frequently observed reason is the formation of thrombosis because of endothelial damage and/or graft malposition during the intraoperative period [6]. In the literature, the acute occlusions developing after the iatrogenic dissection have been reported. Moreover, the metallic clips might very rarely be an iatrogenic reason for graft occlusions. The rate of early-period graft deficiency after the coronary artery bypass graft surgery has been reported to be between $3 \%$ and $12 \%$ [7].

The late-period venous graft deficiency develops as a result of arterialization and progressive changes because of the systemic blood pressure in venous grafts after the CABG. The arterialization ends with the progressive thickening of media layer, and the neointimal formation [8]. The intimal hyperplasia develops 1 month after the CABG operation, and it is not followed in arterial grafts. Although the neointimal hyperplasia is not a reason for stenosis, it also paves the way for atherosclerotic changes. Since the 1st postoperative year, the atherosclerosis is the main reason for saphena vein graft deficiency [9]. As the number of distal anastomosis, also the possibility of surgical technique failures and the consequent failure increases. The length and extension of graft must be very carefully calculated and adjusted in order to perfectly accomplish every anastomosis and prevent from the graft deficiency. Determining the length and direction of each saphena vein graft might be very difficult because of the variability in heart size and saphena vein length. The heart arrested under cardiopulmonary bypass (CPB) for distal anastomosis is empty and loose, whereas the saphena vein is contracted. The heart enlarges after $C P B$, and the saphena vein elongates together with the pressure (Figure 2). All these changes must be taken into account together with the quality of anastomosis in order to prevent the kink of limb of graft remaining long or the stress on graft remaining short [10].

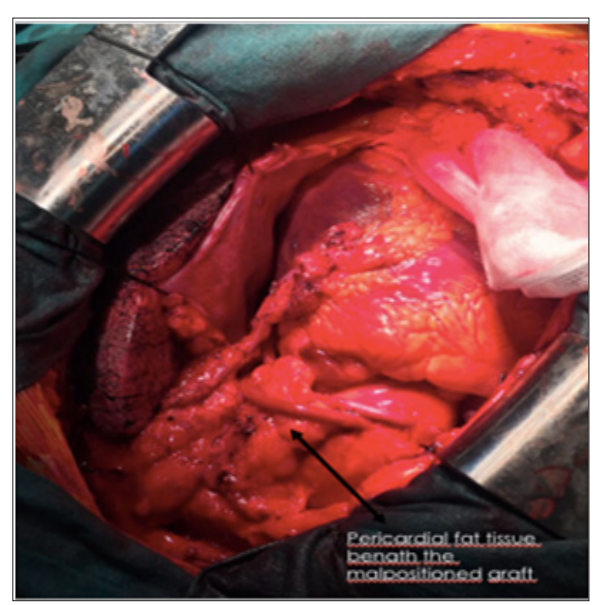

Figure 2 : Reconstructed malposition with pericardial fat tissue, fast, easy, and effectively applicable.

\section{The use of pericardial fat tissue in malposition of venous graft}

Graft malposition or kinking may be a reason for early-period graft occlusion especially for the long grafts. The long grafts are more likely to kink, whereas the short ones are likely to be stressed. One of the most important reasons of inaccurately measuring the length of saphena vein grafts is the inability of estimating the natural volume of heart, the volume of which is smaller during CPB, and consequently the optimal graft length that is needed. It might be very difficult for the surgeons to correct the technical failures that are realized from completion proximal anastomosis in CABG operations or heart achieving its natural volume after the end of cardiopulmonary bypass (CPB). It may force us to renew the anastomosis by placing side or cross clamp in aorta tissue, which has become fragile and calcific especially because of advancing age, and to struggle with the difficult complications. Re-implantation of cross clamp is known to be a disadvantageous option since

a) It creates ischemia on distal coronary site by leaving the other proximal anastomoses out of the cross site,

b) It causes sub-endocardial damage development and distention for myocardium that has to run against the cross clamp right after the $\mathrm{CPB}$, and

c) It prolongs the operation time, as well as it also leads to aortic trauma.

d) As seen in Figure 1, in our cases, in which we realized the kink of saphena vein graft, the use of pericardial fat tissue is a fast, easy, and effective method. See also Figure 2- reconstructed malposition with pericardial fat tissue.

As seen in the figures, the potential gap between saphena vein graft and ascending aorta was buffered by using the autogenetic pericardial fat tissue, and the permanence was achieved by fixing the tissue-compatible fibrin glue. This method can be used in order to prevent the kinking malposition of saphena vein graft, which is longer than needed, and consequent early-period thrombosis. The use of fibrin glue has been reported to prevent the early-period graft damage and hinder the transformation to arterial wall characteristic [11]. Within this context, the fibrin glue directly interacting with the graft is thought to contribute to the successful outcomes of present study even from the aspect of preventing the long-term graft deficiency. In actual and promising studies carried out on the use of stem cells in cardiac regeneration and myocardial infarction, it has been reported that the pericardial fat tissue is richer in myocardial progenitor stem cells, when compared to the other fatty tissues [12].

Given the roles it plays in cardiac tissue repair and initiation of angiogenesis, the topical use of stem cells of pericardial fat tissue is believed both to accelerate the tissue recovery in ischemic myocardial tissue in coronary artery disease and to increase the graft patency from the aspect of arterialization by triggering the angiogenesis in venous grafts rather than initiating the intimal hyperplasia. 


\section{Conclusion}

Despite all the advancements in preventing it, the saphena vein graft deficiency constitutes the majority of negative outcomes achieved after CABG. Although the gene therapy developed in order to prevent the graft deficiency, external graft support systems [13] hybrid grafts, and synthetic conduits are promising, there still is no sufficient proof. We believe that the method presented here is an effective method in order to manage the graft malposition since it prevents

a) the kink-based thrombosis by acting as buffer in kinking point of graft,

b) the long-term graft deficiency by triggering the myocardial regeneration and graft angiogenesis under favor of the topical effect of pericardial stem cells,

c) intimal hyperplasia together with the indirect contribution of fibrin glue used as stabilizer, and this method is

d) an affordable and can be rapidly implemented.

\section{References}

1. Lopes RD, Hafley GE, Allen KB, Ferguson TB, Peterson ED, et al. (2009) Endoscopic versus open vein-graft harvesting in coronary-artery bypass surgery. N Engl J Med 361: 235-244.

2. Hillis LD, Smith PK, Anderson JL, Bittl JA, Bridges CR, et al. (2011) ACCF/ AHA Guideline for coronary artery by pass graft surgery. Circulation 124(23): 2610-2642.

3. Lee MS, Park SJ, Kandzari DE, Kirtane AJ, Fearon WF, et al. (2011) Saphenous vein graft intervention. JACC Cardiovasc Interv 4(8): 831843.

4. Bourassa MG, Fisher LD, Campeau L, Gillespie MJ, Mc Conney (1985) Long-term fate of bypass grafts: the Coronary Artery Surgery Study
(CASS) and Montreal Heart Institute experiences. Circulation 72(6): 7178.

5. Harskamp Ralf E (2013) Saphenous vein graft failure after coronary artery bypass surgery: pathophysiology, management, and future directions. Annals of surgery 257(5): 824-833.

6. Motwani JG, Topol EJ (1998) Aortocoronary saphenous vein graft disease: pathogenesis, predisposition and prevention. Circulation 97(9): 916-931.

7. Ricci M, Karamanoukian HL, D Ancona G, Bergsland J, Salerno TA (2000) Reoperative "off-pump" circumflex revascularization via left thoracotomy: How to prevent graft kinking. Ann Thorac Surg 70(1): 309-310.

8. Roy P, Finci L, Bopp P, Meier B (1989) Emergency balloon angioplasty and digital subtraction angiography in the management of an acute iatrogenic occlusive dissection of a saphenous vein graft. Cathet Cardio vasc Diagn 16(3): 176-179.

9. Muneretto C, Bisleri G, Negri A, Manfredi J, Metra M, et al. (2003) Total arterial myocardial revascularization with composite grafts improves results of coronary surgery in elderly: a prospective randomized comparison with conventional coronary artery bypass surgery. Circulation 108: 1129-1133.

10. Sabik Joseph F (2011) Understanding saphenous vein graft patency. Circulation 124(3): 273-275.

11. Stooker W (2002) Perivenous application of fibrin glue reduces early injury to the human saphenous vein graft wall in an ex vivo model. European Journal of Cardio-Thoracic Surgery 21(2): 212-217.

12. Bayes Genis Antoni (2013) Cardiac adipose tissue: a new frontier for cardiac regeneration? Interventional journal of cardiology 167(1): 2225.

13. Ben Gal Yanai (2013) Expandable external support device to improve Saphenous Vein Graft Patency after CABG. J Cardiothorac Surg 8: 122.

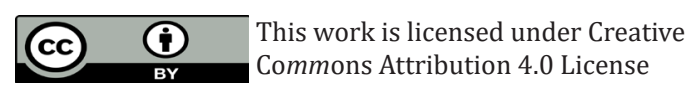

Submission Link: https://biomedres.us/submit-manuscript.php

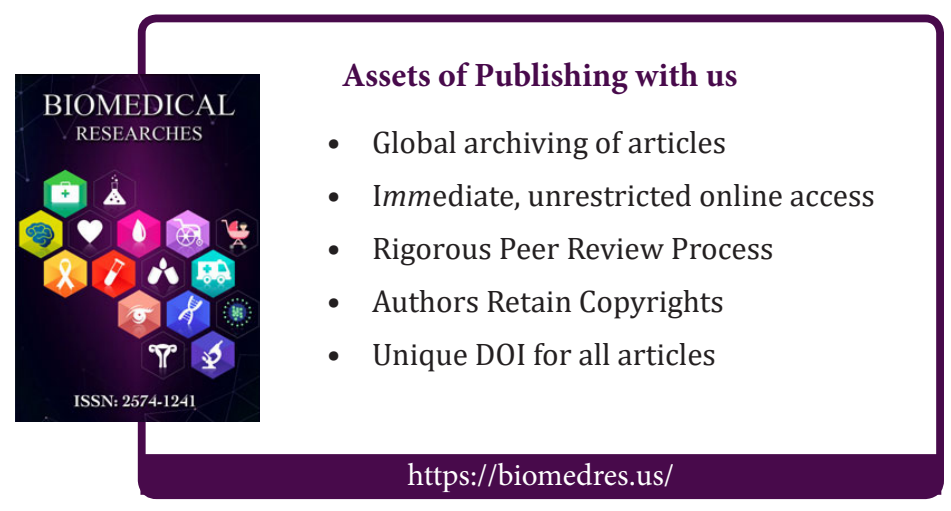

